\title{
The Development of Mobile Culinary Recommendation System Based on Group Decision Support System
}

\author{
https://doi.org/10.3991/ijim.v12i3.7799 \\ Ratih Kartika Dewi $\left.{ }^{\bowtie}\right)$, Mahardeka Tri Ananta, Lutfi Fanani, \\ Komang Candra Brata, Nurizal Dwi Priandani \\ Brawijaya University, Malang, Indonesia \\ ratihkartikad@ub.ac.id
}

\begin{abstract}
Mobile based culinary recommendation system has received significant attention in recent mobile application research. Technique for Order of Preference by Similarity to Ideal Solution (TOPSIS) has regained popularity in supporting multi-criteria decision making due to this method allowing inclusion of many factors and criteria into the decision making process. Previous works on mobile based scenario culinary recommendation system reveal that TOPSIS stand out from other recommendation approaches like AHP and Fuzzy by providing a lightweight computation algorithm that have promising performance in time complexity. However, computing a culinary recommendation using TOPSIS has own limitations especially in the menu judgment processes due to the alternatives priority only include personal preferences for recommendation. In such a culinary recommendation system scenario, users more likely search culinary menus in group instead of alone. This research aims to develop a culinary recommendation system based on group decision support system (GDSS) using TOPSIS that possible to calculate a recommendation by using group preferences instead of personal preferences. The experimental results show that the overall functional of proposed GDSS gives better recommendation result. GDSS using TOPSIS have 100\% rank consistency for 6 group of users with 5 combination of menus. The accuracy testing shows that 83,33\% recommendation of GDSS TOPSIS are match with real user preferences. Furthermore, it can be run well in various type of Android smartphone.
\end{abstract}

Keywords-Mobile Application, Culinary, GDSS, TOPSIS

\section{Introduction}

As advances in information technologies change the computing environment, decision-making process and computations become more trivial. Mobile based culinary recommendation system has received significant attention in recent mobile application research. Simply, put the implementation of multi-criteria decision making in information systems also has a positive impact to improve the economic development of a city as well as the well being of its citizens transaction processes.

Technique for Order of Preference by Similarity to Ideal Solution (TOPSIS) has regained popularity in supporting multi-criteria decision making due to this method 
allowing inclusion of many factors and criteria into the decision making process [2]. The main concept of this method is that the most preferred alternative should have the shortest distance from the positive ideal solution (PIS) and the longest distance from the negative ideal solution (NIS). PIS is the one that maximizes the benefit criteria and minimizes the cost criteria, while the NIS maximizes the cost criteria and minimizes the benefit criteria [4]. Previous works on mobile based scenario culinary recommendation system reveal that TOPSIS stand out from other recommendation approaches like AHP and Fuzzy by providing a lightweight computation algorithm that have promising performance in time complexity [3][1]. This fact make TOPSIS suitable for limited computation devices like smartphones. Recent examples span a implementation range of this algorithm in mobile environment from wireless network selection [5].

However, computing a culinary recommendation using TOPSIS has its own limitations especially in the menu judgment processes due to the alternatives priority only include personal preferences for recommendation [3]. In such a culinary recommendation system scenario, users more likely search culinary menus in group instead of alone. Group preferences data are more complex and relatively different from personal preferences. From these problems we intend to develop a culinary recommendation system based on group decision support system (GDSS) using TOPSIS that possible to calculate a recommendation by using group preferences instead of personal preferences.

The objective of this research is to evaluate the performance and accuracy of TOPSIS that implemented on mobile GDSS culinary recommendation since this algorithm is appropriate to be applied in mobile device platform that have limited computation resources.

\section{Proposed Method}

Group Decision Support system (GDSS) to search for culinary recommendation work by ranking the group of food choice by group of member or user. The built GDSS group would receive input in the form of food preferences from each user. The choice of food menu has three criteria that can be considered which are distance, price, and rating. The process of ranking or recommendation was performed using the Topsis algorithm. The final output of the system was a culinary recommendation that matches the user group preferences.

In general, the steps for designing the TOPSIS algorithm in solving the problem by choosing the best solution are as follows:

1. Develop the normalized decision matrix

Element $r_{i j}$ was a result from the normalization of decision matrix $\mathrm{R}$ with Euclidean length of a vector method which shown in Equation (1).

$$
r_{i j}=\frac{x_{i j}}{\sqrt{\sum_{i=1}^{m} x^{2} i j}}
$$


which :

$$
\begin{aligned}
& r_{i j}=\text { Normalization result of decision matrix } R \\
& i=1,2,3, \ldots, m ; \\
& j=1,2,3, \ldots m ;
\end{aligned}
$$

2. Develop the weighted normalized decision matrix with weight $\mathrm{W}=$ $\left(\mathrm{w}_{1}, \mathrm{w}_{2}, \ldots, \mathrm{w}_{\mathrm{n}}\right)$ which shown in Equation (2).

$$
V=\left[\begin{array}{ccc}
w_{1} r_{11} & \cdots & w_{n} r_{1 n} \\
\vdots & \ddots & \vdots \\
w_{1} r_{m 1} & \cdots & w_{n} r_{m n}
\end{array}\right]
$$

which :

$$
\begin{aligned}
& i=1,2,3, \ldots \mathrm{m} ; \\
& j=1,2,3, \ldots, n ;
\end{aligned}
$$

3. Determine the positive and negative ideal solution. The positive ideal solution was denoted by symbol $\mathrm{A}^{+}$and negative ideal solution was denoted by $\mathrm{A}^{-}$which shown in Equation (3) and Equation (4).

$$
\begin{aligned}
& A^{+}=\left\{\left(\max V_{i j} \mid j \in J\right)\left(\min V_{i j} \mid j \in J^{\prime}\right), i=1,2,3, \ldots m\right\}=\left\{v_{1}^{+}, v_{2}^{+}, \ldots v_{m}^{+}\right\} \\
& A^{-}=\left\{\left(\max V_{i j} \mid j \in J\right)\left(\min V_{i j} \mid j \in J^{\prime}\right), i=1,2,3, \ldots m\right\}=\left\{v_{1}^{-}, v_{2}^{-}, \ldots v_{m}^{-}\right\}
\end{aligned}
$$

which :

$$
\begin{aligned}
& V_{i j}=\text { Element Matrix } V-i \text { row and } j \text { column; } \\
& J=\{j=1,2,3, \ldots, m \text { and } j \text { in related with benefit criteria }\} ; \\
& J^{\prime}=\{j=1,2,3, \ldots, m \text { and } j \text { in related with cost criteria }\} ;
\end{aligned}
$$

4. Separation Measure is a distance measurement from an alternative to positive and negative ideal solution which shown in Equation (5) and Equation (6).

$$
\begin{aligned}
& S_{i}^{+}=\sqrt{\sum_{j=1}^{n}\left(v_{i j}-v_{j}^{+}\right)^{2}} \text {, with } \mathrm{i}=1,2,3, \ldots, \mathrm{n} ; \\
& S_{i}^{-}=\sqrt{\sum_{j=1}^{n}\left(v_{i j}-v_{j}^{-}\right)^{2}} \text {, with } \mathrm{i}=1,2,3, \ldots, \mathrm{n} ;
\end{aligned}
$$

5. Calculate the alternative adjacency to the ideal solution. The relative adjacency from alternative $\mathrm{A}^{+}$to ideal solution ideal $\mathrm{A}^{-}$which shown in Equation (7).

$$
C_{i}^{+}=\frac{S_{i}^{-}}{S_{i}^{-}+S_{i}^{+}} \text {, with } 0<\mathrm{Ci}+<1 \text { and } \mathrm{i}=1,2,3, \ldots, \mathrm{m} ;
$$

6. Alternative Ranking was able to be ranked based on sequence $\mathrm{Ci}^{+}$in descending order. Therefore, the best alternative was the nearest alternative to the positive and negative ideal solution. Alternative with the biggest $\mathrm{Ci}^{+}$was the best solution. 
The use of Topsis algorithm on GDSS was conducted by comparing the alternative ranking value of each decision maker as in Table 1. The result of GDSS Topsis was culinary recommendation with the top ranking decision maker.

Table 1. Matrix GDSS Topsis

\begin{tabular}{|c|c|c|c|c|}
\hline \multirow{2}{*}{ DM Group } & \multicolumn{5}{|c|}{ Alternatives } \\
\cline { 2 - 5 } & $\boldsymbol{A 1}$ & $\boldsymbol{A 2}$ & $\boldsymbol{A 3}$ & $\boldsymbol{A 4}$ \\
\hline DM1 & 1 & 2 & 4 & 3 \\
\hline DM2 & 2 & 3 & 1 & 4 \\
\hline DM3 & 1 & 3 & 2 & 4 \\
\hline
\end{tabular}

\section{Implementation}

The mobile culinary recommendation system developed in this research begins when all data has been obtained. The data that we used are name of restaurant, address, location based on latitude and longitude, operational hours, food or drink menu, price, and restaurant facility. All data are acquired by manually and processed into digital data using back-end system that is designed and implemented.

During implementation, menu is the most important data in this system. The system asks the user to specify menu they want to eat and, the user assign one of the food and drink menu, price, distance and ratings they experienced based on the database. When the user finds one of them they can mark it as chosen one by clicking the check box, fill the ratings star, and push the price \& distance bar. A selection of the menu that the user marked as a chosen, this allows the system to acquire knowledge about the general user preferences. These are found by predicting and computed the user needs by a Group Decision Support System method and gave one recommendation for the others. Figure 1 shows the result of culinary recommendation system.
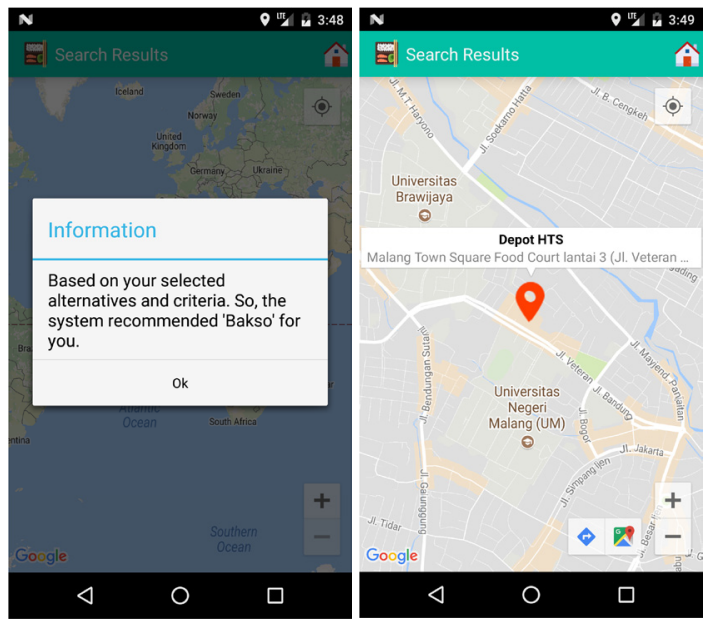

Fig. 1. Recommendation Results 


\section{$4 \quad$ Results}

In this work we conducted 2 types of testing to test the TOPSIS GDSS, such as rank consistency and accuracy. A rank consistency test is performed to determine whether the rankings generated by the GDSS are consistent with changes in the number of different decision makers. While accuracy testing is done to determine whether the GDSS recommendation results in accordance with the actual circumstances. In the test of accuracy and rank consistency is done 30 different tests using 6 combinations of decision makers who each tested against the five food menu combinations. The combination of decision makers group in this test uses 6 test scenarios, ie a combination of 2 decision makers (users 1 and 2), 3 decision makers (users 1,2 and 3), 4 decision makers (users 1, 2, 3 and 4) 5 decision makers (users 1, 2, 3, 4 and 5), 6 decision makers (users 1, 2, 3, 4, 5 and 6), and 7 decision makers (users 1, 2, 3, 4, 5, 6 and 7). These 7 decision makers have different weights against each of the criteria as listed in Table 2.

Table 2. User preference based on criteria

\begin{tabular}{|c|c|c|c|c|c|c|c|}
\hline & User 1 & User 2 & User 3 & User 4 & User 5 & User 6 & User 7 \\
\hline Price & 1.67 & 0.2 & 3.3 & 1.95 & 1.67 & 0.5 & 1.8 \\
\hline Distance & 0.33 & 3.8 & 0.1 & 0.2 & 1.67 & 2.7 & 2.5 \\
\hline Rating & 0.2 & 0.1 & 0.2 & 1.67 & 0.2 & 0.1 & 0.5 \\
\hline
\end{tabular}

Tables 3 show one of the menu combinations which can be tried according to price, distance and rating for each food.

Table 3. Combination of Menu (1)

\begin{tabular}{|l|c|c|c|}
\hline & Price (Rp) & Distance (m) & Rating \\
\hline Nasi Goreng Ria Djenaka & 14900 & 1.2 & 4 \\
\hline Nasi Goreng Sea Food Ala Wakul & 15000 & 1.6 & 3.8 \\
\hline Nasi Goreng 69 & 19000 & 1 & 4.2 \\
\hline Nasi Goreng Vegetarian & 22000 & 2.9 & 4.2 \\
\hline Nasi Goreng Mawut & 11500 & 1.8 & 3.8 \\
\hline
\end{tabular}

\subsection{Rank Consistency Test}

After 30 different tests using 6 combinations of decision-makers each tested on 5 combinations of food menu as listed in Table 4, it can be concluded that the results are the same in each combination of different number of users. it shows GSS TOPSIS that is built $100 \%$ consistent. This indicates that the combination of decision makers group does not change the order of rank recommendation, so that GDSS TOPSIS constructed is consistent in the recommendation. 


\subsection{Accuracy Test}

The Accuracy is done by comparing the amount of data that matches the overall amount of real situation data. For example in the first experiment the system gives a recommendation of Nasi Goreng 69, if 2 users in question choose Nasi Goreng 69 then the value of true positive is worth 1 or match. Table 4 show the example of accuracy test results in six cases.

Table 4. Combination of Menu (1)

\begin{tabular}{|c|l|l|l|c|}
\hline $\begin{array}{c}\text { Number of } \\
\text { User }\end{array}$ & Menu Combination & \multicolumn{1}{|c|}{ GDSS Result } & User Result & Value \\
\hline \multirow{4}{*}{1} & 1 & Nasi goreng 69 & Nasi goreng 69 & True \\
\cline { 2 - 5 } & 2 & Soto babat & Chicken katsu & False \\
\cline { 2 - 5 } & 3 & Tahu telor & Tahu telor & True \\
\cline { 2 - 5 } & 4 & Beef/chicken burger & Beef/chicken burger & True \\
\hline \multirow{3}{*}{$\ldots$} & 5 & Big Mac & Big Mac & True \\
\hline \multirow{3}{*}{6} & $\ldots$ & $\ldots$ & $\ldots$ & Nrue \\
\cline { 2 - 5 } & 1 & Nasi goreng 69 & Sasi goreng 69 & True \\
\cline { 2 - 5 } & 2 & Soto babat & Tahu telor & True \\
\cline { 2 - 5 } & 3 & Tahu telor & Beef/chicken burger & True \\
\cline { 2 - 5 } & 4 & Beef/ chicken burger & Taco roll & False \\
\hline
\end{tabular}

Based on the data are shown in the table 4, it can be calculated the value of the accuracy of TOPSIS GDSS in the following formula:

$$
\text { Accuracy }=25 /(30) * 100 \%=83,333 \%
$$

In this testing yield an accuracy of $83.333 \%$. This shown that the built TOPSIS GDSS provides accurate data recommendations for 25 of 30 data. Five incorrect data caused by the choice of users whose personal preference is different for each person. This can be due to the criteria used to select only using 3 criteria, namely price, distance and rating. In the next study can be proposed the addition of the number of criteria.

\section{Conclusions}

Test was conducted using rank consistency and accuracy test. Rank consistency was used to show if the recommendation is consistent if different group of user combinated. This work shows that the development of GDSS using TOPSIS have $100 \%$ rank consistency for 6 group of users with 5 combination of menus. We also conducted test of accuracy to show if GDSS TOPSIS have accurate recommendation compared by the real data. It shows $83,33 \%$ recommendation of GDSS TOPSIS are match with real data. 


\section{Acknowledgment}

This research was supported by Research and Community Service Brawijaya University (LPPM-UB) in beginner research grant. We thank our colleagues from Media, Game and Mobile research group and also friends from culinary Micro, Small, Medium Enterprises (MSME) who provided insight and expertise that greatly assisted this research.

\section{$7 \quad$ References}

[1] Hamdani, and Retantyo Wardoyo. "The complexity calculation for group decision making using TOPSIS algorithm." AIP Conference Proceedings. Eds. Tri Rini Nuringtyas, et al. Vol. 1755. No. 1. AIP Publishing, 2016.

[2] Kelemenis, Alecos, and Dimitrios Askounis. "A new TOPSIS-based multi-criteria approach to personnel selection." Expert systems with applications 37.7 (2010): 4999-5008. https://doi.org/10.1016/j.eswa.2009.12.013

[3] Triantaphyllou, Evangelos. "Multi-criteria decision making methods." Multi-criteria decision making methods: A comparative study. Springer US, 2000. 5-21. https://doi.org/10.1007/978-1-4757-3157-6 2

[4] Wang, Ying-Ming, and Taha MS Elhag. "Fuzzy TOPSIS method based on alpha level sets with an application to bridge risk assessment." Expert systems with applications 31.2 (2006): 309-319. https://doi.org/10.1016/j.eswa.2005.09.040

[5] B. Bakmaz, Z. Bojkovic, and M. Bakmaz, "Network Selection Algorithm for Heterogeneous Wireless Environment," IEEE Int. Symp. on Personal, Indoor \& Mobile Radio Comms., PIMRC 2007.

[6] Maharani, Septya, Heliza Rahmania Hatta, and Gery Merdiko. "Decision Support System of Culinary Recommendations using AHP and TOPSIS Methods with Map Visualization." Bali International Seminar on Science and Technology (BISSTECH) II. 2014.

[7] Mamat, Nur Jumaadzan Zaleha, and Jacob Karikottu Daniel. "Statistical analyses on time complexity and rank consistency between singular value decomposition and the duality approach in AHP: A case study of faculty member selection." Mathematical and Computer Modelling 46.7 (2007): 1099-1106. https://doi.org/10.1016/j.mcm.2007.03.025

[8] Melvin, Alexander. "Decision-making using the analytic hierarchy process (AHP) and SAS/IML." SESUG, Paper SD-04 (2012).

[9] Nurrachman, Risza, Aryo Pinandito, Ratih Kartika Dewi. 2016. Metode AHP-Topsis untuk Sistem Rekomendasi Kuliner Kota Malang. Universitas Brawijaya (2016).

[10] Pinandito, A., C. P. Wulandari, and R. K. Dewi. "Culinary Recommendation System Using Analytical Hierarchy Process on Google Android Platform." International Conference on Engineering and Information Technology (ICEIT). 2015.

[11] Pinandito, Aryo, et al. "Alternatives Weighting in Analytic Hierarchy Process of Mobile Culinary Recommendation System using Fuzzy", (2016).

[12] Saaty, Thomas L. "Decision making with the analytic hierarchy process." International journal of services sciences 1.1 (2008): 83-98. https://doi.org/10.1504/IJSSCI.2008. 017590

[13] Shih, Hsu-Shih, Huan-Jyh Shyur, and E. Stanley Lee. "An extension of TOPSIS for group decision making." Mathematical and Computer Modelling 45.7 (2007): 801-813. https://doi.org/10.1016/j.mcm.2006.03.023

[14] Wegener, Ingo. Complexity theory: exploring the limits of efficient algorithms. Springer Science \& Business Media, 2005 


\section{Authors}

Ratih Kartika Dewi, Mahardeka Tri Ananta, Lutfi Fanani, Komang Candra Brata, and Nurizal Dwi Priandani are with Department of Computer Science, Faculty of Computer Science, Brawijaya University, Malang - East Java, Indonesia.

Article submitted 06 October 2017. Final acceptance 28 April 2018. Final version published as submitted by the authors. 